\title{
Investigation of Stress Relief Heat treatment on Carbon Steel AISI 1045 Weld
}

\author{
Prachya Peasura, ${ }^{\mathrm{a}, *}$ \\ a, ${ }^{*}$ Department of Production Technology Education, Faculty of Industrial Education and Technology, King Mongkut's \\ University of Technology Thonburi, Thongkru, Bangkok Thailand 10140 \\ *Corresponding Author: prachya.pea@kmutt.ac.th
}

\begin{abstract}
This research studied the effect of stress relief heat treatment on mechanical properties and microstructure in carbon steel AISI 1045 grade. The specimen was carbon steel AISI 1045 which thickness of $6 \mathrm{~mm}$. The AISI 1045 specimens were welded utilizing a gas metal arc welding (GMAW) process. After welding, the stress relief heat treatment parameters examined in this study included stress relief temperature of 450,500,550, 600 and stress relief treatment time of 1 and 5 hour. The resulting materials were examined using the full factorial design of experiments to determine the resulting material hardness, tensile strength testing and microstructure observed with optical microscopy (OM) following ASTM standard. A factorial analysis, which was conducted on the interaction between the stress relief heat treatment temperature and time to the hardness of the heat affected zone and tensile strength, had a $95 \%$ confidence level. The results show that the highest hardness and tensile strength achieved during the SRHT was $222 \mathrm{HV}$ and 622 MPa for a SRHT time of $5 \mathrm{hr}$. and a SRHT temperature of $550{ }^{\circ} \mathrm{C}$. The stress relief heat treatment analysis indicates that a sustainable in the amount of pearlite results in better hardness and tensile strength.
\end{abstract}

Keywords: Stress Relief Heat treatment, Carbon steel, Hardness, Tensile strength, Full factorial design.

\section{Introduction}

The medium carbon steel of AISI 1045 steel has good machinability in normalized as well as the hot rolled condition. Based on the recommendations given by the machine manufacturers, operations like tapping, milling, broaching, drilling, turning and sawing etc. can be carried out on AISI 1045 steel using suitable feeds, tool type and speeds. Medium carbon steel are alloys of iron and carbon in which carbon does not usually exceed $0.5 \%$, manganese, silicon chromium each do not exceed $0.60 \%$. The other alloying elements are usually not more than the amount of residue properties and weldability of carbon steel, these are based on the carbon content. In the elements have only limited impact on medium carbon steel pronounced changes in carbon steel weldability of the talk on the carbon content in the nest of 0:30 to 0:50 carbon steels containing about 0.3 percent carbon and manganese content and relatively low with good weldability. As the carbon content of steel will increase welding process must be designed to avoid the formation of a lot of hard martensite in the heat affected zone. [1-2]

A stress relief heat treatment (SRRT) processes is requirement after welding processes. The matensite phase and resulting high hardness can lead to cracking in the heat affected zone (HAZ) if the metal cannot yield to relieve welding stress [3]. The fatigue strength of welded joints is generally irrespective from the base material yield strength due to notch effects at the weld toe or root, tensile residual stresses by the thermo-mechanical joining process and significant changes in local material properties within the heat-affected zone. An effective way to increase the potential of light-weight design exhibits the application of post-weld treatments. [4] The analysis of variance value stress-relief heat treatment parameters with full factorial design. Many experiments involve the study of the effects of two factor is an interaction between the factors. [5]

This research focuses on the effects of SRHT on the microstructure in the heat-affected zone and mechanical properties for carbon steel AISI1045 grade. The optimum 
values for the variables in the SRHT were determined by a full factorial design of experiments. In this case, the effects of the SRHT time and temperature and their interactions were determined.

\section{Methodology}

\subsection{Materials and Welding Methods}

The material used for the test specimens was AISI 1045. Weld specimens were $6.00 \mathrm{~mm}$. thickness. Details on the chemical composition of the material are given in Table 1.

Table 1 Chemical composition of carbon steel AISI

1045 by weight $(\%)$

\begin{tabular}{|c|c|c|c|c|c|c|c|c|}
\hline $\mathrm{C}$ & $\mathrm{Mn}$ & $\mathrm{Si}$ & $\mathrm{Cu}$ & $\mathrm{Cr}$ & $\mathrm{P}$ & $\mathrm{S}$ & $\mathrm{Mo}$ & $\mathrm{Ni}$ \\
\hline 0.46 & 0.81 & 0.42 & 0.09 & 0.12 & 0.02 & 0.01 & 0.03 & 0.06 \\
\hline
\end{tabular}

The specimens were welded utilizing a gas metal arc welding (GMAW) process. The electrode was used ER70S6 with electrode $0.8 \mathrm{~mm}$ in diameter. The welding current was set at 150 amps and a direct current electrode negative (DCEN) was used. Carbon dioxide (100\%) was used as the shielding gas with a flow rate of 15 liters/minute. After welding, the specimens were treated by SRHT in two factors. The first factors consisted of SRHT temperature at 450, 500, 550 and $600{ }^{\circ} \mathrm{C}$. The second factor was the SRHT time of 1 and $5 \mathrm{hrs}$. Each aging treatment condition was conducted randomly, with each condition being tested a total of three replicate.

The welded specimens were sectioned transversely to the weld and polished using standard metallographic techniques. Polished samples for Optical microscope (OM) following ASTM E3 - 11 standard guide for preparation of metallographic specimens [6]. The weld specimens were examined and analyzed by the inverted hardness and tensile strength test following ASTM E92-82 standard test method for vickers hardness of metallic materials in heat affected zone (HAZ) [7].

\subsection{Experimental Design}

In this study, the full factorial design experimental design was studied interaction on hardness. The hypothesis that level of confidence $95 \%$ ( P-value $<0.05$ ). The factors used in the study are as follows. Each excremental treatment was to 3 replicated show in Table 2 .

Hypothesis of experimental.

$\mathrm{H} 0 ;(\alpha \beta) \mathrm{ij}=0$ is SRHT time and SRHT temp no interaction hardness and tensile strength

$\mathrm{H} 1 ;(\alpha \beta) \mathrm{ij} \neq 0$ is SRHT time and SRHT temp interaction hardness and tensile strength

Table 2. Design of experiment

\begin{tabular}{|c|c|c|c|c|c|}
\hline $\begin{array}{c}\text { Std } \\
\text { Order }\end{array}$ & $\begin{array}{c}\text { Run } \\
\text { Order }\end{array}$ & $\begin{array}{c}\text { TRHT } \\
\text { Thr.) }\end{array}$ & $\begin{array}{c}\text { SRHT } \\
\text { Temp } \\
\left({ }^{\mathbf{C}} \text { ) }\right.\end{array}$ & $\begin{array}{c}\text { Hardness } \\
\text { (HV) }\end{array}$ & $\begin{array}{c}\text { Tensile } \\
\text { Strength } \\
\text { (MPa) }\end{array}$ \\
\hline 1 & 3 & 1 & 450 & 177.1 & 574.5 \\
\hline 2 & 8 & 1 & 450 & 182.2 & 579.3 \\
\hline 3 & 16 & 1 & 450 & 178.8 & 573.2 \\
\hline 4 & 12 & 1 & 500 & 198.1 & 585.5 \\
\hline 5 & 18 & 1 & 500 & 193.7 & 580.3 \\
\hline 6 & 1 & 1 & 500 & 196.8 & 587.8 \\
\hline 7 & 22 & 1 & 550 & 201.0 & 592.3 \\
\hline 8 & 17 & 1 & 550 & 204.7 & 597.4 \\
\hline 9 & 23 & 1 & 550 & 200.4 & 591.2 \\
\hline 10 & 21 & 1 & 600 & 206.0 & 610.4 \\
\hline 11 & 2 & 1 & 600 & 204.1 & 607.2 \\
\hline 12 & 6 & 1 & 600 & 207.1 & 609.3 \\
\hline 13 & 19 & 5 & 450 & 196.1 & 591.1 \\
\hline 14 & 11 & 5 & 450 & 193.7 & 585.2 \\
\hline 15 & 7 & 5 & 450 & 197.7 & 592.1 \\
\hline 16 & 10 & 5 & 500 & 203.8 & 603.7 \\
\hline 17 & 20 & 5 & 500 & 209.0 & 610.4 \\
\hline 18 & 14 & 5 & 500 & 205.1 & 604.3 \\
\hline 19 & 4 & 5 & 550 & 224.1 & 622.7 \\
\hline 20 & 15 & 5 & 550 & 222.7 & 624.4 \\
\hline 21 & 5 & 5 & 550 & 220.9 & 618.8 \\
\hline 22 & 24 & 5 & 600 & 214.7 & 608.1 \\
\hline 23 & 13 & 5 & 600 & 210.7 & 602.2 \\
\hline 24 & 9 & 5 & 600 & 213.5 & 610.4 \\
\hline
\end{tabular}

\subsection{Results of hardness}

\section{Experimental result}

The hardness was the test on mechanical property of weld for measuring hardness which using 24 sample for each testing according to ASTM E92-82 standard test method for vickers hardness of metallic materials. The hardness of the as received material is $175 \mathrm{HV}$. The statistical analysis was used to obtain the results and conclusions of the trial through analyzing the variability in the full factorial design are shown in Fig. 1 and Table 2. 


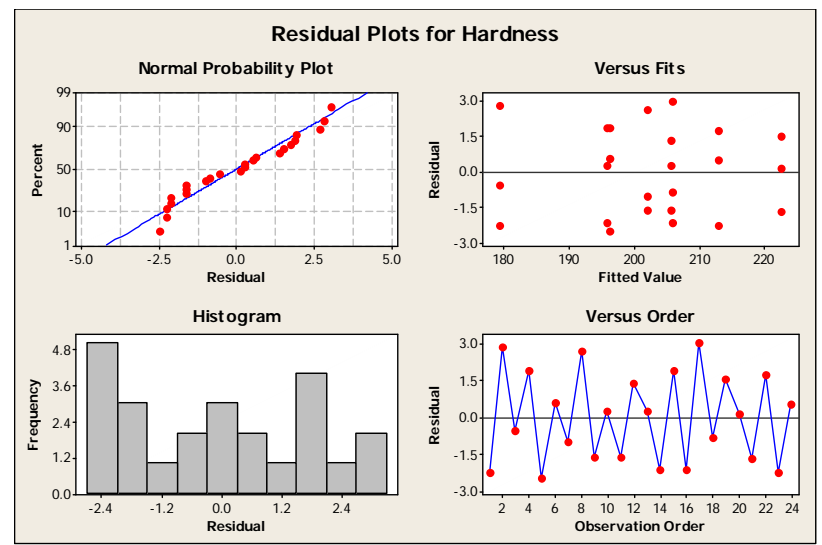

Fig.1 Residual plot for hardness

Fig.1 shows residual plot for hardness. The statistical data check was performed and validated by experimental models. The hypothesis is that the pattern of the residuals obtained from the experimental data adheres to the principle $\varepsilon i j \sim$ NID $\left(0, \sigma^{2}\right)$. Residuals are assumed to be independent and normally distributed. The mean 0 and $\sigma^{2}$ is near stability to the experimental data. The results showed that the data are randomness. The result concluded that the data from the experimental results for hardness.

Table 3 Analysis of variance (ANOVA) for hardness.

\begin{tabular}{|l|c|c|c|c|c|c|}
\hline \multicolumn{1}{|c|}{ Source } & D & Seq SS & Adj SS & $\begin{array}{c}\text { Adj } \\
\text { MS }\end{array}$ & F & P \\
\hline $\begin{array}{l}\text { SRHT } \\
\text { Time }\end{array}$ & 1 & $\begin{array}{c}1093.5 \\
0\end{array}$ & $\begin{array}{c}1093.5 \\
0\end{array}$ & $\begin{array}{c}1093.5 \\
0\end{array}$ & $\begin{array}{c}231.7 \\
8\end{array}$ & $\begin{array}{c}0.00 \\
0\end{array}$ \\
\hline $\begin{array}{l}\text { SRHT } \\
\text { Temp }\end{array}$ & 3 & $\begin{array}{c}2201.7 \\
1\end{array}$ & $\begin{array}{c}2201.7 \\
1\end{array}$ & 733.90 & 155.5 & 0.00 \\
\hline $\begin{array}{l}\text { SRHT } \\
\text { Time*SRH } \\
\text { T Temp }\end{array}$ & 3 & 167.22 & 167.22 & 55.74 & 11.81 & 0.00 \\
\hline Error & 16 & 75.49 & 75.49 & 4.72 & & 0 \\
\hline Total & 23 & 3537.9 & & & & \\
\hline$R^{2}=97.87 \%$ & & 1 & $\mathrm{R}^{2}(\mathrm{adj})=96.93 \%$ & & \\
\hline
\end{tabular}

The SRHT time and temperature interaction effects on the hardness were determined for confidence level of 95\% (PValue $<0.05)$. The results indicate that the data could be predicted using the model. The $\mathrm{R}^{2}$ (adj) of the collected data was approximately $96.93 \%$, which shows that the response can be described by the experimental factors as show in Table3.

Fig. 2 shows the, effects of the SRHT temperature and time on the hardness. An interaction between these variables is seen when the lines in the plot are not parallel. Regarding the improvement of the hardness of AISI 1045 by SRHT the line plot indicates that there was strong interaction between the SRHT temperature of the treatment and the SRHT time it was applied. The results show that the highest hardness achieved during the SRHT was $222 \mathrm{HV}$ for a SRHT time of $5 \mathrm{hr}$. and a SRHT temperature of $550^{\circ} \mathrm{C}$.

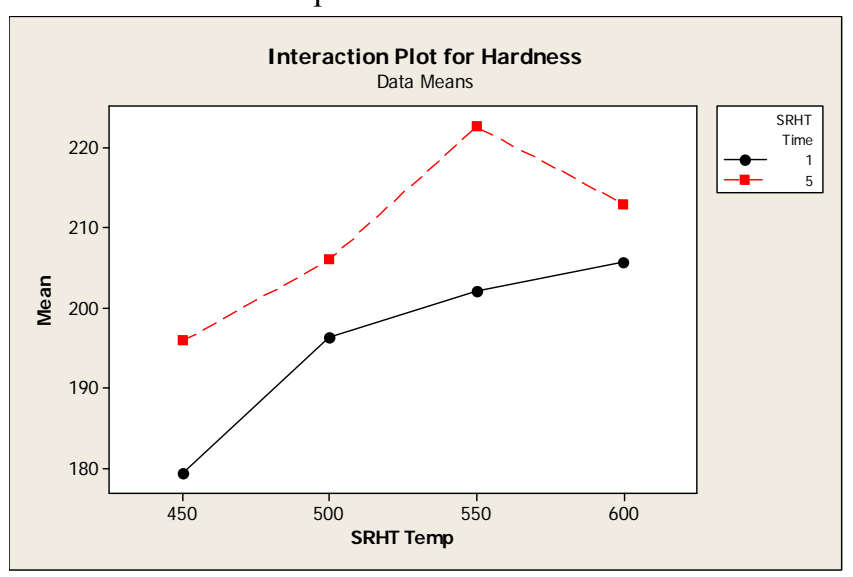

Fig.2 Interaction plot for hardness

\subsection{Tensile Strength Analysis}

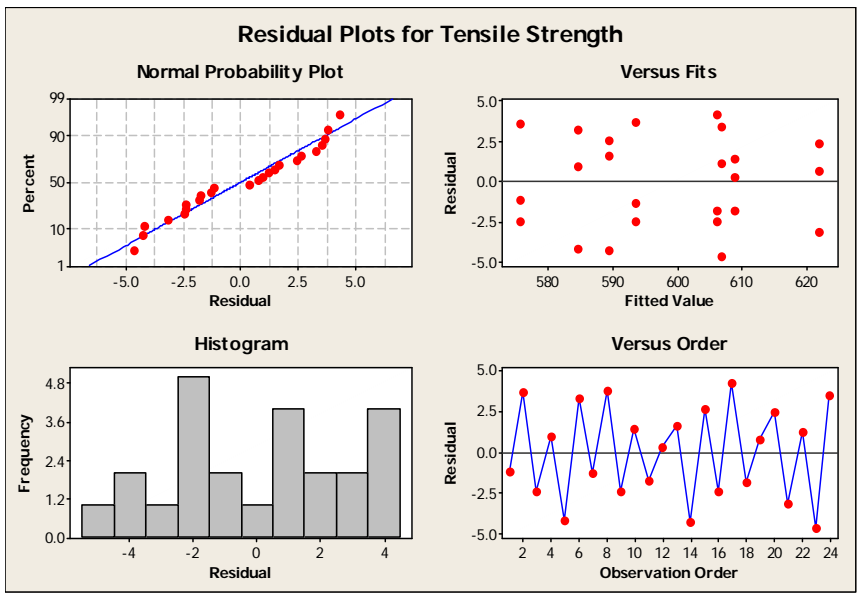

Fig.3 Residual plot for tensile strength.

Figure 3 shows the normal distribution of tensile strength analysis. The normal distribution was used to test the residual distribution. The data results show that the residuals were distributed along a straight line from the middle of the histogram. The residual data of the distribution was a normal shape and the residuals were estimated to have a normal distribution. 
Table 4 Analysis of variance (ANOVA) for tensile strength.

\begin{tabular}{|l|c|c|c|c|c|c|}
\hline \multicolumn{1}{|c|}{ Source } & D & Seq SS & Adj SS & $\begin{array}{c}\text { Adj } \\
\text { MS }\end{array}$ & F & P \\
\hline $\begin{array}{l}\text { SRHT } \\
\text { Time }\end{array}$ & 1 & $\begin{array}{c}1426.0 \\
4\end{array}$ & $\begin{array}{c}1426.0 \\
4\end{array}$ & $\begin{array}{c}1426.0 \\
4\end{array}$ & $\begin{array}{c}123.4 \\
0\end{array}$ & $\begin{array}{c}0.00 \\
0\end{array}$ \\
\hline $\begin{array}{l}\text { SRHT } \\
\text { Temp }\end{array}$ & 3 & $\begin{array}{c}2636.0 \\
6\end{array}$ & $\begin{array}{c}2636.0 \\
6\end{array}$ & 878.69 & 76.03 & 0.00 \\
\hline $\begin{array}{l}\text { SRHT } \\
\text { Time*SRH } \\
\text { T Temp }\end{array}$ & 3 & 770.03 & 770.03 & 256.68 & 22.21 & 0.00 \\
\hline Error & 16 & 184.91 & 184.91 & 11.56 & & 0 \\
\hline Total & 23 & 5017.0 & & & & \\
\hline R $20.31 \%$ & & & $\mathrm{R}^{2}(\mathrm{adj})=94.70 \%$ & & \\
\hline
\end{tabular}

Table4 show the analysis of variance for two factors interaction effects on the tensile strength were determined for confidence level of $95 \%$. The tensile strength results indicate that the data could be approximated using the model. The $\mathrm{R}^{2}$ (adj) of the collected data was predict $94.70 \%$, which shows that the response can be described by the experimental factors.

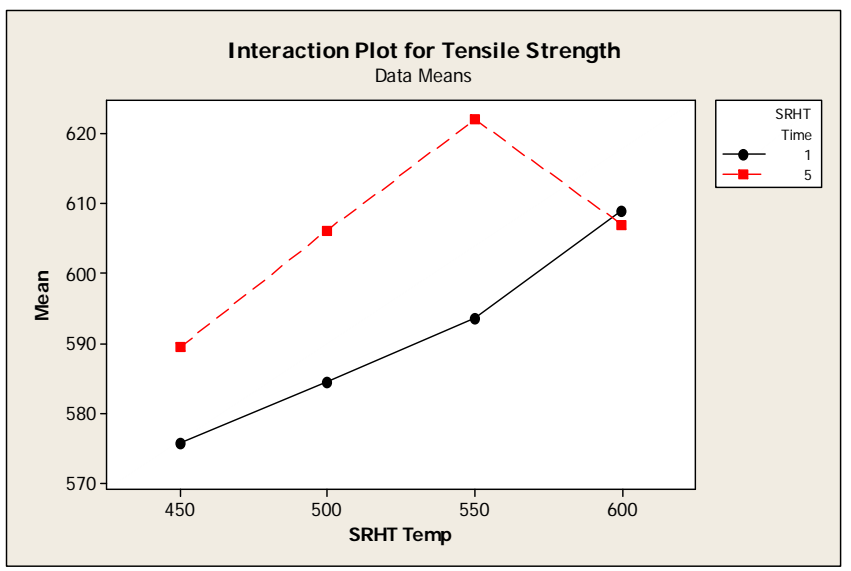

Fig.4 Interaction plot for tensile strength.

Fig. 4 shows the, influence of the SRHT factors on the tensile strength. An interaction between these factors showed in the lines in the plot are not parallel. The line plot indicates that there was strong interaction between the two SRHT factors. The tensile strength analysis show that the highest tensile strength achieved during the SRHT was $622 \mathrm{MPa}$ for a SRHT time of $5 \mathrm{hr}$. and a SRHT temperature of $550^{\circ} \mathrm{C}$.

\subsection{Correlation of the tensile strength and hardness}

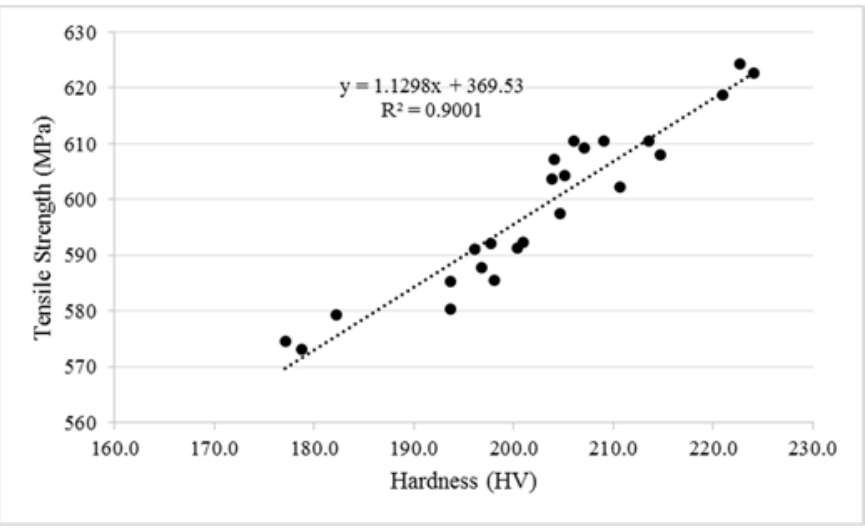

Fig. 5. The correlation of Vickers hardness with the tensile strength.

Fig. 5 shows the correlation of hardness with the tensile strength for the SRHT factors of temperator and time. The figure shows a linear relationship of hardness with the tensile strength, where the correlation coefficient $R^{2}$ of 0.90 suggests appropriate correlation.

\subsection{Microstructure analysis}

As observed in the heat affected zone (HAZ) shown in Fig. 6 , the microstructure at the weld joints is ferrite in the parent phase and pearlite phase from the SRHT [8].

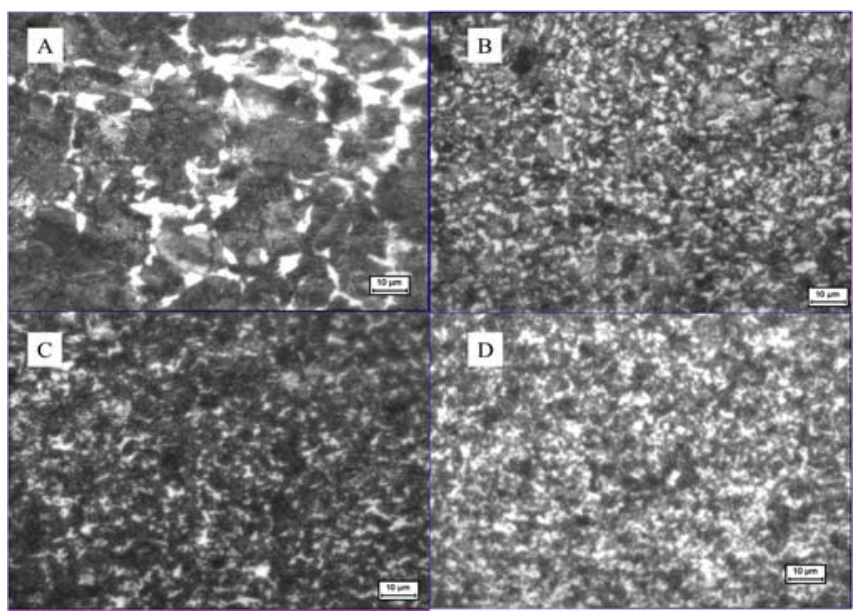

Fig. $6 \mathrm{HAZ}$ microstructure A. SRHT temperature $450{ }^{\circ} \mathrm{C}$ and SRHT $1 \mathrm{hr}$., B. SRHT temperature $550{ }^{\circ} \mathrm{C}$ and SRHT $1 \mathrm{hr}$., C. SRHT temperature $550{ }^{\circ} \mathrm{C}$ and SRHT5 hr., D. SRHT temperature $600{ }^{\circ} \mathrm{C}$ and SRHT $5 \mathrm{hr}$.

The optical micrograph in Fig. 6 compares the microstructure in the specimens. Figure 6(A) also shows the microstructure for the specimen with a SRHT treatment at $450{ }^{\circ} \mathrm{C}$ for $1 \mathrm{hr}$., which shows an increase in density of the large pearlite and lamellar pearlite. The hardness tends to increase for the PWHT treatment of $1 \mathrm{hr}$. at $550^{\circ} \mathrm{C}$. The 
perlite dissolve into the grain, whereas fine pearlite remain, as shown in Fig. 6(B). The pearlite have a fine grain, which results in a maximum material hardness. Figure $6(\mathrm{C})$ shows a SRHT treatment of $550^{\circ} \mathrm{C}$ and $1 \mathrm{hr}$., where the fine pearlite and intensity. At a SRHT temperature of $600^{\circ} \mathrm{C}$ for $5 \mathrm{hr}$., over-SRHT in the HAZ results in pearlite intensity of reduced, which causes the lowest hardness value of all tested samples, [9-10] as shown in Fig. 6(D).

\section{Conclusions}

In this work, the effects of the SRHT on the hardness, tensile strength and microstructure of AISI 1045 welds were studied. SRHT temperatures of $450{ }^{\circ} \mathrm{C}, 500{ }^{\circ} \mathrm{C}, 550{ }^{\circ} \mathrm{C}$ and $600{ }^{\circ} \mathrm{C}$ and SRHT times of 1 and 2 hours. The heat-affected zone microstructures and the hardness distribution were examined and analyzed. The results indicate that the SRHT temperature and time used during the SRHT greatly affect both the mechanical properties and microstructure. The results from this study are summarized as follows:

1. The parameters used in the experimental SRHT temperature and time interaction of confidence level of $95 \%$ which results can be applied to design this experiment is to decide on the selection of appropriate parameters in SRHT parameter as weld on AISI 1045.

2. The resulting SRHT weld specimens have an increased hardness compared to the weld specimen's initial hardness of $175 \mathrm{HV}$. When the PWHT time increased, the hardness for all SRHT temperature increased until a SRHT parameters of $550^{\circ} \mathrm{C}$ and $22 \mathrm{hr}$.

3. The microstructure of AISI 1045 has pearlite and ferrite when the SRHT temperature and time increase, which affects the pearlite density and fine grain in the parent phase.

4. The correlation of the tensile strength with the hardness resulted in a reasonable linear relationship, with a correlation coefficient $R^{2}$ of 0.90 .

\section{References}

(1) American Welding Society, "Welding Handbook 7 edition, Metals and Their Weldability", American welding society, Vol. 4, pp.14, 1982.

(2) J.C. Chang, B.S. Kim, N.H. Heo., "Stress Relief Cracking on the Weld of T/P 23 Steel", Procedia Engineering, Vol. 10, pp.734-739, 2011.
(3) H. Granjon, "Fundamentals of Welding metallurgy", Abington publishing, pp.178-183, 1991.

(4) Martin Leitner, Stefan Gerstbrein, Markus Ottersböck, Michael Stoschka, "Fatigue Strength of HFMI-treated and Stress-relief Annealed High-strength Steel Weld Joints", Procedia Engineering, Vol. 133, pp. 477-484, 2015.

(5) Douglas C. Montgomery, "Design and analysis of experiments", John Wiley and son, pp.197, 1991.

(6) The American society of testing and materials, "ASTM E3-11 Standard Guide for Preparation of Metallographic Specimens", The American society of testing and materials, 2012.

(7) The American society of testing and materials, "ASTM E92-82 standard test method for vickers hardness of metallic materials", The American society of testing and materials, 2003.

(8) American society for metal, "Metals hand book ninth edition", American society for metal, Vol.9, pp.170183, 1985.

(9) G.M. Evans and N. Bailey., "Metallurgy of basic weld metal", Abington publishing, pp. 108-117, 1997.

(10) Prachya Peasura, "Application of $2^{3}$ Factorial Design Experiments for Gas Tungsten Arc Welding Parameters on ASTM A36 Steel Welds", Applied Mechanics and Materials, Vol. 246-247, pp. 707-711, 2013. 